\title{
MicroRNAs and SIRT1: A Strategy for Stem Cell Renewal and Clinical Development?
}

\author{
Kenneth Maiese* \\ Cellular and Molecular Signaling, Newark, New Jersey 07101, USA \\ Running Title: miRNAs and SIRT1
}

\begin{abstract}
Small non-coding ribonucleic acids (RNAs), known as microRNAs (miRNAs), are now becoming recognized as significant agents that can affect the onset and progression of numerous disorders throughout the body. In particular, miRNAs also may determine stem cell renewal and differentiation. Intimately tied to the ability of miRNAs to govern stem cell proliferation are the proliferative pathways of silent mating type information regulation 2 homolog 1 (Saccharomyces cerevisiae) (SIRT1) and the cell survival mechanisms of autophagy that can be coupled to the activity of the mechanistic target of rapamycin (mTOR). Targeting miRNAs that oversee SIRT1 activity offers interesting prospects for the translation of these pathways into efficacious clinical treatment programs for a host of disorders. Yet, as work in this area progresses, a number of challenges unfold that impact whether manipulation of non-coding RNAs and SIRT1 can finely guide stem cell renewal and differentiation to reach successful clinical outcomes.
\end{abstract}

\section{Stem Cell Clinical Utility: Considerations for miRNAs and SIRT1}

Stem cells are increasingly being considered for the development of novel strategies for multiple disorders throughout the body that can affect the nervous system, cardiovascular system, immune system, metabolism, and cancer. One of the challenges for applications that rely upon stem cell proliferation and differentiation is the protection and maintenance of stem cell populations. For example, specific pathways, such as the mechanistic target of rapamycin (mTOR), can be critical for stem cell proliferation [1]. In the absence of mTOR activity, trophoblast growth can be inhibited with the failure to establish embryonic stem cells [2]. Loss of mTOR activity in neural stem cells results in reduced lineage expansion and blocked differentiation and neuronal production [3]. During aging, activity of mTOR may be reduced and leads to reduced neurogenesis [4] and a reduction in the proliferation of active neural stem cells [5]. The degree of activity of the mTOR pathway also can impact the differentiation of stem cell populations. Inhibition of mTOR activity can promote cell differentiation into astrocytic cells [6] and lead to earlier neuronal and astroglial differentiation [7]. Furthermore, increased activity of mTOR can foster tumor growth [8, 9]. Blockade of mTOR activity can limit the population of cancer stem cells that can cause disease recurrence and therapeutic resistance [10].

Interestingly, loss of mTOR activity can promote the induction of autophagy [11] and lead to an increase in silent mating type information regulation 2 homolog 1 (Saccharomyces cerevisiae) (SIRT1) activity that also is vital for stem cell proliferation [12]. In human embryonic stem cells challenged with oxidative stress, autophagy leads to cell protection and requires SIRT1 activity with the concurrent inhibition of mTOR [13]. SIRT1 appears to have an inverse relationship with mTOR to increase stem cell survival $[12,14]$. During the down-regulation of mTOR, SIRT1 promotes neuronal growth [15] and increases mesangial cell proliferation during high glucose exposure [16]. SIRT1 can limit the expression of aged mesenchymal stem cell phenotypes [17], prevent senescence and impaired differentiation of endothelial progenitor cells [18], and improve cardiomyoblast survival [19]. SIRT1 can influence neuronal differentiation as well. If SIRT1 is repressed with the parallel induction of heat shock protein-70, neural differentiation and the maturation of embryonic cortical neurons can ensue [20]. Differentiation of human embryonic stem cells into motoneurons also occurs in the absence of SIRT1 [21]. As a proliferative agent, increased activity of SIRT1 under some circumstances can lead to the expansion of cancer stem cells. SIRT1 can maintain acute myeloid leukemia stem cells and result in resistance against chemotherapy [22], promote endometrial cell tumor growth through lipogenesis [23], and foster oncogenic transformation of neural stem cells [24].

One strategy that may successfully regulate SIRT1 activity and stem cell proliferation for effective translation into clinical treatment programs may involve the modulation of microRNAs (miRNAs). MiRNAs are composed of 19-25 nucleotides and are small noncoding ribonucleic acids (RNAs). MiRNAs oversee gene expression by silencing targeted messenger RNAs (mRNAs) translated by specific genes. These small non-coding ribonucleic acids may play an important role to influence stem cell proliferation and cellular differentiation. For example, over-expression of miR-381 can lead to neural stem cell proliferation and prevent differentiation into astrocytes [25]. MiR134, miR-296, and miR-470 can serve to target Oct4, Sox2, and Nanog coding regions to lead to stem cell differentiation [26]. In regards to

Correspondence to: Kenneth Maiese, MD, Cellular and Molecular Signaling, USA, E-mail: wntin75@yahoo.com

Key words: Akt, apoptosis, autophagy, forkhead, FoxO, miRNA, mTOR, mTORC1, mTORC2, programmed cell death, small non-coding RNA, sirtuins, SIRT1, stem cells

Received: October 02, 2015; Accepted: October 05, 2015; Published: October 08,2015 
SIRT1, neuronal differentiation can occur through miR-34a that leads to decreased SIRT1 expression and DNA-binding of p53 in mouse neural stem cells [27]. However, during increased SIRT1 activity, miR$34 \mathrm{a}$ results in astrocytic differentiation that appears to be independent of SIRT1 [27]. Under other conditions, a reduction in miRNA activity with increased SIRT1 expression may be necessary for stem cell proliferation. Silencing of miR-195 in old mesenchymal stem cells that allows increased SIRT1 activity restores anti-aging factors expression that include telomerase reverse transcriptase, protein kinase B (Akt), and the forkhead transcription factor FOXO1 [28] to promote stem cell proliferation [29]. In addition, loss of miR-204 that can target SIRT1 can allow SIRT1 to foster the proliferation of spermatogonial stem cells [30]. Given the inverse relationship between mTOR and SIRT1, proliferation of stem cells also may require increased SIRT1 activity in combination with the inhibition or dysfunction of mTOR signaling that is controlled by miRNAs [31].

Targeting miRNAs provides an intriguing format for the control of stem cell proliferation and differentiation through pathways that involve SIRT1. Yet, several considerations must be addressed for the development of novel strategies with stem cells, miRNAs, and SIRT1. For example, the cellular level of activity of SIRT1 that is controlled by miRNAs may present an important caveat for the development of strategies for clinical disorders, since the presence of SIRT1 has the capability to either promote or retard stem cell proliferation and differentiation. To a similar degree, the level of SIRT1 activity can ultimately influence cellular survival. Sufficient SIRT1 activity is required for cellular cardiovascular protection [32-35] and neuronal protection [36-38]. However, a reduction in SIRT1 activity may be necessary for growth factor protection with insulin growth factor-1 [39]. Other considerations involve the role of programmed cell death pathways that involve autophagy or apoptosis as well as mTOR with miRNAs and SIRT1. SIRT1 can promote autophagy induction during inhibition of mTOR activity that may be beneficial to stem cell proliferation. Yet, non-coding mRNAs may block autophagy pathways through SIRT1 and prevent potentially reparative stem cell pathways such as angiogenesis [40]. In addition, some miRNAs, such as miR$34 \mathrm{a}$, have been reported to lead to apoptosis, impaired cell vitality, and aggravated senescence in mesenchymal stem cells through the activation of the SIRT1 and FOXO3a [41], clearly suggesting that SIRT1 activity regulated by miRNAs can greatly affect not only stem cell proliferation and differentiation, but also stem cell survival.

\section{Acknowledgments}

This research was supported by the following grants to Kenneth Maiese: American Diabetes Association, American Heart Association, NIH NIEHS, NIH NIA, NIH NINDS, and NIH ARRA.

\section{Competing Interests}

There are no conflicts of interest to declare.

\section{References}

1. Maiese K (2015) Stem cell guidance through the mechanistic target of rapamycin. World J Stem Cells 7: 999-1009. [Crossref]

2. Gangloff YG, Mueller M, Dann SG, Svoboda P, Sticker M, et al. (2004) Disruption of the mouse mTOR gene leads to early postimplantation lethality and prohibits embryonic stem cell development. Mol Cell Biol 24: 9508-9516. [Crossref]

3. Hartman NW, Lin TV, Zhang L, Paquelet GE, Feliciano DM, et al. (2013) mTORC1 targets the translational repressor 4E-BP2, but not S6 kinase 1/2, to regulate neural stem cell self-renewal in vivo. Cell Rep 5: 433-444. [Crossref]
4. Maiese K (2014) Driving neural regeneration through the mammalian target of rapamycin. Neural Regen Res 9: 1413-1417. [Crossref]

5. Romine J, Gao X1, Xu XM1, So KF2, Chen J3 (2015) The proliferation of amplifying neural progenitor cells is impaired in the aging brain and restored by the mTOR pathway activation. Neurobiol Aging 36: 1716-1726. [Crossref]

6. Sato A, Sunayama J, Matsuda K, Tachibana K, Sakurada K, et al. (2010) Regulation of neural stem/progenitor cell maintenance by PI3K and mTOR. Neurosci Lett 470: 115-120. [Crossref]

7. Magri L, Cambiaghi M, Cominelli M, Alfaro-Cervello C, Cursi M, et al. (2011) Sustained activation of mTOR pathway in embryonic neural stem cells leads to development of tuberous sclerosis complex-associated lesions. Cell Stem Cell 9: 447462. [Crossref]

8. Maiese K (2015) Neuronal Activity, Mitogens, and mTOR: Overcoming the Hurdles for the Treatment of Glioblastoma Multiforme. J Transl Sci 1: 2. [Crossref]

9. Yang C, Zhang Y, Zhang Y, Zhang Z, Peng J, et al. (2015) Downregulation of cancer stem cell properties via mTOR signaling pathway inhibition by rapamycin in nasopharyngeal carcinoma. Int J Oncol 47: 909-917. [Crossref]

10. Kolev VN, Wright QG, Vidal CM, Ring JE, Shapiro IM, et al. (2015) PI3K/mTOR dual inhibitor VS-5584 preferentially targets cancer stem cells. Cancer Res 75: 446-455. [Crossref]

11. Maiese K, Chong ZZ, Shang YC, Wang S (2013) mTOR: on target for novel therapeutic strategies in the nervous system. Trends Mol Med 19: 51-60. [Crossref]

12. Maiese K (2015) SIRT1 and stem cells: In the forefront with cardiovascular disease, neurodegeneration and cancer. World J Stem Cells 7: 235-242. [Crossref]

13. Ou X, Lee MR, Huang X, Messina-Graham S, Broxmeyer HE (2014) SIRT1 positively regulates autophagy and mitochondria function in embryonic stem cells under oxidative stress. Stem Cells 32: 1183-1194. [Crossref]

14. Chong ZZ, Shang YC, Wang S, Maiese K (2012) SIRT1: new avenues of discovery for disorders of oxidative stress. Expert Opin Ther Targets 16: 167-178. [Crossref]

15. Guo W, Qian L, Zhang J, Zhang W, Morrison A, et al. (2011) Sirt1 overexpression in neurons promotes neurite outgrowth and cell survival through inhibition of the mTOR signaling. J Neurosci Res 89: 1723-1736. [Crossref]

16. Zhang S, Cai G, Fu B, Feng Z, Ding R, et al. (2012) SIRT1 is required for the effects of rapamycin on high glucose-inducing mesangial cells senescence. Mech Ageing Dev 133: 387-400. [Crossref]

17. Liu X, Chen H, Zhu W, Chen H, Hu X, et al. (2014) Transplantation of SIRT1engineered aged mesenchymal stem cells improves cardiac function in a rat myocardial infarction model. J Heart Lung Transplant 33: 1083-1092. [Crossref]

18. Lemarié CA1, Shbat L, Marchesi C, Angulo OJ, Deschênes ME, et al. (2011) Mthf deficiency induces endothelial progenitor cell senescence via uncoupling of eNOS and downregulation of SIRT1. Am J Physiol Heart Circ Physiol 300: H745-753. [Crossref]

19. Passariello CL, Zini M, Nassi PA, Pignatti C, Stefanelli C (2011) Upregulation of SIRT1 deacetylase in phenylephrine-treated cardiomyoblasts. Biochem Biophys Res Commun 407: 512-516. [Crossref]

20. Liu DJ, Hammer D, Komlos D, Chen KY, Firestein BL, et al. (2014) SIRT1 knockdown promotes neural differentiation and attenuates the heat shock response. J Cell Physiol 229: 1224-1235. [Crossref]

21. Zhang Y, Wang J, Chen G, Fan D, Deng M (2011) Inhibition of Sirt1 promotes neura progenitors toward motoneuron differentiation from human embryonic stem cells Biochem Biophys Res Commun 404: 610-614. [Crossref]

22. Li L, Osdal T, Ho Y, Chun S, McDonald T, et al. (2014) SIRT1 activation by a c-MYC oncogenic network promotes the maintenance and drug resistance of human FLT3-ITD acute myeloid leukemia stem cells. Cell Stem Cell 15: 431-446. [Crossref]

23. Lin L, Zheng X, Qiu C, Dongol S, Lv Q, et al. (2014) SIRT1 promotes endometrial tumor growth by targeting SREBP1 and lipogenesis. Oncol Rep 32: 2831-2835. [Crossref]

24. Lee JS, Park JR, Kwon OS, Lee TH, Nakano I, et al. (2015) SIRT1 is required for oncogenic transformation of neural stem cells and for the survival of "cancer cells with neural stemness" in a p53-dependent manner. Neuro Oncol 17: 95-106. [Crossref]

25. Shi X, Yan C, Liu B, Yang C, Nie X, et al. (2015) miR-381 Regulates Neural Stem Cell Proliferation and Differentiation via Regulating Hes1 Expression. PLoS One 10: e0138973. [Crossref]

26. Tay Y, Zhang J, Thomson AM, Lim B, Rigoutsos I (2008) MicroRNAs to Nanog, Oct4 
and Sox 2 coding regions modulate embryonic stem cell differentiation. Nature 455 : 1124-1128. [Crossref]

27. Aranha MM, Santos DM, Solá S, Steer CJ, Rodrigues CM (2011) miR-34a regulates mouse neural stem cell differentiation. PLoS One 6: e21396. [Crossref]

28. Maiese K (2015) FoxO proteins in the nervous system. Anal Cell Pathol (Amst) 2015: 569392. [Crossref]

29. Okada M, Kim HW, Matsu-Ura K, Wang YG, Xu M, et al. (2015) Abrogation of AgeInduced MicroRNA-195 Rejuvenates the Senescent Mesenchymal Stem Cells by Reactivating Telomerase. Stem Cells. [Crossref]

30. Hua J (2015) miR-204 regulated the proliferation of dairy goat spermatogonial stem cells via targeting to Sirt1. Rejuvenation Res. [Crossref]

31. Jung CJ, Iyengar S, Blahnik KR, Jiang JX, Tahimic C, et al. (2012) Human ESC self-renewal promoting microRNAs induce epithelial-mesenchymal transition in hepatocytes by controlling the PTEN and TGFbeta tumor suppressor signaling pathways. Mol Cancer Res 10: 979-991. [Crossref]

32. Hou J, Chong ZZ, Shang YC, Maiese K. (2010) Early apoptotic vascular signaling is determined by Sirt1 through nuclear shuttling, forkhead trafficking, bad, and mitochondrial caspase activation. Curr Neurovasc Res 7: 95-112. [Crossref]

33. Hou J, Wang S, Shang YC, Chong ZZ, Maiese K (2011) Erythropoietin Employs Cell Longevity Pathways of SIRT1 to Foster Endothelial Vascular Integrity During Oxidant Stress. Curr Neurovasc Res 8: 220-235. [Crossref]

34. Kilic U, Gok O, Bacaksiz A, Izmirli M, Elibol-Can B, et al. (2014) SIRT1 gene polymorphisms affect the protein expression in cardiovascular diseases. PLoS One 9: e90428. [Crossref]

35. Marampon F, Gravina GL, Scarsella L, Festuccia C, Lovat F, et al. (2013) Angiotensinconverting-enzyme inhibition counteracts angiotensin II-mediated endothelial cel dysfunction by modulating the p38/SirT1 axis. J Hypertens 31: 1972-1983. [Crossref]

36. Kim DW, Kim YM, Kang SD, Han YM, Pae HO (2012) Effects of Resveratrol and trans3,5,4'-Trimethoxystilbene on Glutamate-Induced Cytotoxicity, Heme Oxygenase-1, and Sirtuin 1 in HT22 Neuronal Cells. Biomol Ther (Seoul) 20: 306-312. [Crossref]

37. Wang S, Chong ZZ, Shang YC, Maiese K (2013) WISP1 neuroprotection requires FoxO3a post-translational modulation with autoregulatory control of SIRT1. Curr Neurovasc Res 10: 54-69. [Crossref]

38. Zhang J, Feng X, Wu J, Xu H, Li G, et al. (2014) Neuroprotective effects of resveratrol on damages of mouse cortical neurons induced by $\beta$-amyloid through activation of SIRT1/Akt1 pathway. Biofactors 40: 258-267. [Crossref]

39. Sansone L, Reali V, Pellegrini L, Villanova L, Aventaggiato M, et al. (2013) SIRT1 silencing confers neuroprotection through IGF-1 pathway activation. $J$ Cell Physiol 228: 1754-1761. [Crossref]

40. Ramalinga M, Roy A, Srivastava A, Bhattarai A, Harish V, et al. (2015) MicroRNA-212 negatively regulates starvation induced autophagy in prostate cancer cells by inhibiting SIRT1 and is a modulator of angiogenesis and cellular senescence. Oncotarget. [Crossref]

41. Zhang F, Cui J, Liu X, Lv B, Liu X, et al. (2015) Roles of microRNA-34a targeting SIRT1 in mesenchymal stem cells. Stem Cell Res Ther 6: 195. [Crossref]

Copyright: $\odot 2015$ Maiese K. This is an open-access article distributed under the terms of the Creative Commons Attribution License, which permits unrestricted use, distribution, and reproduction in any medium, provided the original author and source are credited. 